\title{
Hybrid materials precursor to natural bentonite in the decontamination of Alizarin Yellow from aqueous solutions
}

\author{
Ralte Malsawmdawngzela ${ }^{1}$, Sarikokba ${ }^{1}$, Thanhmingliana ${ }^{2}$, Diwakar Tiwari $^{{ }^{\dagger}}$, Seung Mok Lee ${ }^{3}$ \\ ${ }^{1}$ Department of Chemistry, School of Physical Sciences, Mizoram University, Aizawl-796004, India \\ ${ }^{2}$ Department of Chemistry, Pachhunga University College, Mizoram University, Aizawl-796001, India \\ ${ }^{3}$ Department of Environmental Engineering, Catholic Kwandong University, Gangneung 25601, Republic of Korea
}

\begin{abstract}
The present study aims to investigate the insights of Alizarin Yellow removal by hybrid materials precursor to natural bentonite. The hybrid materials employed are bentonite modified with hexadecyltrimethylammonium bromide (HDTMA) (BnH) and aluminium pillared HDTMA bentonite $(\mathrm{BnAH})$. Surface morphology of materials are obtained with scanning electron microscopy-Energy dispersive X-ray analysis (SEM-EDX). The batch reactor operations conducted in the removal of Alizarin Yellow by these solids for various parametric studies which enabled to deduce the mechanism involved at solid/solution interface. Sorption capacity and selectivity was increased significantly using hybrid materials in the removal of AY. Hybrid materials showed very high removal capacity of AY and apparently unaffected at varied $\mathrm{pH}(4.0-10.0)$ and sorptive concentrations 1.0 to $25.0 \mathrm{mgL}^{-1}$. Kinetic studies indicated that an apparent equilibrium occurred within 5-10 min of contact and the kinetic data was better fitted to the pseudo-second-order kinetic model. The percent removal of AY was not affected by increasing the background electrolyte (NaCl) concentration to $0.1 \mathrm{molL}^{-1}$ and in presence of several co-existing ions. It is revealed that the hybrid materials are found more organophilic and AY molecule bound with strong forces at the surface of hybrid materials.
\end{abstract}

Keywords: Alizarin Yellow, Hybrid materials, Organophilic materials, Pillared materials, Sorption mechanism, Strong bonding

\section{Introduction}

Rapid growth of modern textile industries has led to an excessive discharge of wastes containing dyes and pigments. A report stated that around $10-15 \%$ of the dye produced is lost annually during the textile dyeing process and final processes [1]. Dye compounds are non-biodegradable, persistent in nature, stable to light thereby disturbing the process of photosynthesis in the aquatic environment and are difficult to eliminate because of aromatic structure from water bodies [2-8]. More than 5,000 years, natural dyes, for instance, indigo have been employed for coloring but due to the low cost and availability of new colors, natural dyes are being replaced by the synthetic dyes [9]. Alizarin Yellow, an azo dye, 5-(3-Nitrophenylazo) salicylic acid sodium salt is produced by the diazo coupling reaction and readily soluble in water. It is used in wool, leather, paper, fibers, leather, plastics, food, pharmaceuticals, paints and lacquers industries [9-11]. Several biological and physicochemical treatments such as oxidation, coagulation, acti- vated sludge processes, filtration, photocatalysis, membrane filtration and adsorption are employed in the removal of dye compounds from wastewaters. However, some of these methods are expensive, generate even more toxic by-products and sometimes show limited efficiency [12-14]. Therefore, adsorption is a common and viable method to be employed for the removal of dyes from wastewaters due to its low-cost, easy process and effective since no hazardous by-products are formed in the overall process [15-20].

Clay minerals are natural adsorbent and are found useful in the remediation of aquatic environments contaminated with a variety of water pollutants. The presence of exchangeable cations, electrical charge, micro-porosity and surface functional groups makes clay mineral a good natural adsorbent. However, clay minerals show less efficiency towards several anionic and organic contaminants. Therefore, to increase its sorption capacity towards such pollutants, modification of clay minerals with suitable organic molecules, grafting, treating with acid and alkali, pillaring with poly(hydroxo-metal) cations and cross-linking are interesting alter-
This is an Open Access article distributed under the terms of the Creative Commons Attribution Non-Commercial License (http://creativecommons.org/licenses/by-nc/3.0/) which permits unrestricted non-commercial use, distribution, and reproduction in any medium, provided the original work is properly cited.

Copyright (C) 2022 Korean Society of Environmental Engineers
Received February 26, 2021 Accepted November 17, 2021

${ }^{\dagger}$ Corresponding author

E-mail: diw_tiwari@yahoo.com

Tel: +91-9862323015 Fax: +91-389-2330834

ORCID: 0000-0002-9177-9704 
natives which enhances the applicability of natural clay materials for remediation of contaminated waters [21, 22]. Suitable organic molecules are introduced utilizing the aluminol and silanol groups of clay in the surface modifications or even to functionalize the clay materials. This eventually enhances the sorption efficiency of modified clay materials towards several recalcitrant pollutants from aqueous solutions [23]. Bentonite is a natural layered phyllosilicate, made up of interchanging tetrahedral and octahedral sheets (T:O) in the ratio of 2:1. The silicon ion and aluminium ion in the crystal are replaced by lower valent metal cations such as calcium, sodium, magnesium etc. resulting in the net negative charge of the clay surface. Bentonite is having large specific surface area, high cation exchange capacity (CEC) and high porosity [24, 25]. Bentonite is usually employed in order to remove and reduce the dispersion of toxic contaminants in soil, air and water [26-28]. To increase the affinity of clay minerals with less polar matrices, bentonite was modified with quaternary alkylammonium ions which result in changing the silicate surface from hydrophilic to organophilic enabling adsorption site for the remediation of contaminants of organic in nature from soil and water [29]. Hybrid materials achieved by exchanging clay cations and organic cations are employed for the decontamination of wastewater contaminated with different non-polar organic contaminants (NOC) as well. Further, hybrid materials obtained by pillaring of clay minerals with poly(hydroxo-metal) cations and then intercalated with an appropriate organic cations are useful for treatment of wastewater and greater interest for organic pollutants, due to good settling capacity and easy to separate solid phase from aqueous solutions [30]. Therefore, the present communication is intended to utilize the synthesized hybrid bentonite materials in the decontamination of aqueous solutions contaminated with Alizarin Yellow. The mechanism involved at the solid/solution interface is extensively carried out employing various physico-chemical parametric studies.

\section{Materials and Methods}

\subsection{Materials}

Bentonite was collected from Bhuj, Gujarat, India and washed with distilled water to remove impurities and dried in an oven at $90^{\circ} \mathrm{C}$ overnight. The dried bentonite is made powdered and sieved to obtain 100 BSS (British Standard Sieve) mesh particle size (0.150 $\mathrm{mm}$ ). The cation exchange capacity (CEC) of bentonite was found $68.34 \mathrm{meg} / 100 \mathrm{~g}$ [30]. Alizarin Yellow and hexadecyltrimethylammonium bromide (HDTMA) was obtained from Sigma-Aldrich, USA. Sodium chloride (Extrapure) and Glycine were obtained from HiMedia, India. Cadmium(II) nitrate, copper(II) sulphate, aluminium(III) chloride and oxalic acid were obtained from Merck, India. Further, ethylenediaminetetraacetic acid was obtained from Qualigens, India.

\subsection{Methodology}

\subsubsection{Organoclay and inorgano-organoclay preparation}

The wet cation exchange process was employed for the modification of bentonite with hexadecyltrimethylammonium bromide (HDTMA). The detailed process of modification was described ear- lier and the hybrid material obtained is denoted as $\mathrm{BnH}$ [30]. In brief the HDTMA solution (equivalent to 1:1 cation exchange capacity of bentonite) and bentonite was refluxed for $48 \mathrm{~h}$ at $60^{\circ} \mathrm{C}$. The supernatant was decanted and bentonite was washed with excess of water and dried at $90^{\circ} \mathrm{C}$ for overnight. Likewise, a simple wet synthesis was employed to pillar the bentonite with aluminium followed by introducing the HDTMA using the known method described previously and the materials was denoted as $\mathrm{BnAH}[30$, 31 . In brief the pillaring aluminium solution $\left(0.2 \mathrm{molL}^{-1}\right)$ was mixed with equal volume of sodium hydroxide solution $\left(0.4 \mathrm{molL}^{-1}\right)$. The solution mixture was aged for $7 \mathrm{~d}$ and then HDTMA solution (equivalent to 1:1 cation exchange capacity of bentonite) was added. The slurry was stirred for $5 \mathrm{~h}$ at $25^{\circ} \mathrm{C}$ and was kept for $2 \mathrm{~d}$. The supernatant was decanted and the solid was washed with excess of water and dried at $90^{\circ} \mathrm{C}$. The point of zero charges $\left(\mathrm{pH}_{\mathrm{pzc}}\right)$ of the solid materials were obtained by the known acid base titration method as described elsewhere [32, 33]. In brief, 5.0 g each of solid was taken in two beakers each having $500 \mathrm{~mL}$ of distilled water. Both the beakers are kept under stirring and titrated with $0.1 \mathrm{molL}^{-1}$ of nitric acid and $0.1 \mathrm{molL}^{-1}$ of sodium hydroxide solutions. The $\mathrm{pH}$ was recorded using the $\mathrm{pH}$ meter. Further, the $\mathrm{pH}_{\mathrm{PZC}}$ was obtained by the point at which the curve crossed the line at which $\mathrm{pH}_{\text {final }}=\mathrm{pH}_{\text {initial }}$.

\subsubsection{Characterization and morphology of hybrid material}

The FT-IR data of the pristine bentonite and modified bentonite were determined using FT-IR machine (Bruker, Tensor 27, USA by KBR disk method). Similarly, the surface morphology was obtained by field emission scanning electron microscopy (FE-SEM; S-4700, Hitachi, Japan) images. The X-ray diffraction (XRD) data was obtained by the X-ray diffraction machine (PANalytical, Netherland; Model X'Pert PRO MPD). The BET Analyzer Macsorb HM machine (Model-1201) Japan was employed to obtain the specific surface area, pore volume and pore size of the solid materials.

Real wastewater sample was collected from the municipal wastewater treatment plant, Chite, Aizawl Mizoram, India. The water sample was filtered and subjected for various water quality parameters using a Multi-photometer (HI98194, Hanna Instruments, USA). The total organic/inorganic carbon and elemental analysis were obtained using the TOC analyser (TOC-VCPH/CPN, Shimadzu, Japan) and Atomic Absorption Spectrometer (AA-7000 Series, Shimadzu, Japan), respectively.

\subsubsection{Removal of Alizarin Yellow}

$100 \mathrm{mgL}^{-1}$ stock solution of Alizarin Yellow (AY) was prepared in purified water. The stock solution of AY was further diluted to obtain the required experimental concentrations of AY. 10.0 $\mathrm{mgL}^{-1}$ of AY solutions $(50.0 \mathrm{~mL})$ were placed in different polyethylene bottles and the $\mathrm{pH}$ were adjusted by dropwise addition of $0.1 \mathrm{M} \mathrm{HCl}$ or $\mathrm{NaOH}$ solution. To these solutions, $0.1 \mathrm{~g}$ (100 $\mathrm{mg}$ ) of pristine bentonite or modified bentonite powder was added. These bottles were kept in an automatic incubator shaker (Incubator Shaker, TM Weiber, ACMAS Technologies Pvt. Ltd., India) for $24 \mathrm{~h}$ at $25^{\circ} \mathrm{C}$ in order to achieve the equilibria between the solid/solution interface. The bottles were taken out, centrifuged for $10 \mathrm{~min}$ at $1,200 \mathrm{rpm}$ and the $\mathrm{pH}$ was checked again and recorded as equilibrium $\mathrm{pH}$. The supernatant solution was subjected for the absorb- 
ance measurements using a UV-Vis spectrophotometer (Model UV1, Thermo Electron Corporation, USA). The absorbance was recorded at $350 \mathrm{~nm}$ since $\lambda_{\max }$ for AY was obtained at this wavelength. AY concentration ranging from $1.0-25.0 \mathrm{mgL}^{-1}$ was used to obtain the calibration line for AY at the $\mathrm{pH}$ specified. Further, the concentration of AY was prepared from 1.0 to $25.0 \mathrm{mgL}^{-1}$ to study the effect of sorptive concentration on the removal of AY by hybrid materials at constant $\mathrm{pH} 7.0$ and constant temperature $25^{\circ} \mathrm{C}$. Results are presented as percent removal of $\mathrm{AY}$ as a function of initial AY concentration $\left(\mathrm{mgL}^{-1}\right)$. The elimination of AY on the modified materials was studied at different intervals of time at constant $\mathrm{pH} 7.0$ with initial concentration of AY of $10.0 \mathrm{mgL}^{-1}$. The results were plotted as percent removal of AY as a function of time. The effect of background electrolyte concentration on the removal of $\mathrm{AY}$ was studied by varying the concentration of $\mathrm{NaCl}$ from 0.0001 to $0.1 \mathrm{molL}^{-1}$ at constant $\mathrm{pH}$ of 7.0 having AY concentration of $10.0 \mathrm{mgL}^{-1}$. Results obtained were plotted as percent removal of AY as a function of background electrolyte concentration. The presence of co-existing ions viz., ethylenediaminetetraacetic acid, oxalic acid, glycine, $\mathrm{Cd}(\mathrm{II}), \mathrm{Pb}(\mathrm{II})$ and $\mathrm{Cu}(\mathrm{II})$ in the removal of AY was studied at constant $\mathrm{pH} 7.0$ with co-ions concentrations of $50.0 \mathrm{mgL}^{-1}$ and AY concentration $10.0 \mathrm{mgL}^{-1}$. Results were presented as percent removal of AY in the presence of different co-ions.

Real wastewater sample was collected from the municipal wastewater treatment plant, Chite, Aizawl Mizoram, India. The water sample was filtered and subjected for various water quality parameters using a Multi-photometer (HI98194, Hanna Instruments, USA). The total organic/inorganic carbon and elemental analysis were obtained using the TOC analyser (TOC-VCPH/CPN, Shimadzu, Japan) and Atomic Absorption Spectrometer (AA-7000 Series, Shimadzu, Japan), respectively.

\section{Results and Discussion}

\subsection{Characterization of the Materials}

The modified materials along with the pristine bentonite were characterized by FT-IR and reported previously [30]. The IR data implied that the organic molecule is successfully introduced within the bentonite framework. The XRD analysis is conducted for pristine and modified samples as detailed previously [30, 34]. The existence of sharp diffraction peaks with $\mathrm{d}$-spacing for these materials is confirmed by the X-ray diffraction data. The XRD data is compared with the standard ICDD (International Centre for Diffraction Data) reference pattern. The quantitative estimation confirmed that the bentonite is having 44.72, 24.16, 1.81 and $32.38 \%$ of quartz, smectite, kaolinite and illite, respectively.

Nitrogen adsorption and desorption data is utilized to obtain pore volume, BET specific surface area and pore sizes of $\mathrm{Bn}, \mathrm{BnH}$ and $\mathrm{BnAH}$ solids. The specific surface area of $\mathrm{Bn}, \mathrm{BnH}$ and $\mathrm{BnAH}$ were $81.85,4.69$ and $9.54 \mathrm{~m}^{2} \mathrm{~g}^{-1}$, respectively. Similarly, specific pore volume is estimated as $0.011,0.049$ and $0.076 \mathrm{~cm}^{3} \mathrm{~g}^{-1}$, respectively. On the other hand, the pore size was found to be 4.97, 35.61 and $28.43 \mathrm{~nm}$ respectively for $\mathrm{Bn}, \mathrm{BnH}$ and $\mathrm{BnAH}$ solids. Results indicated that high BET specific surface area of pristine bentonite with low pore size and pore volume is primarily
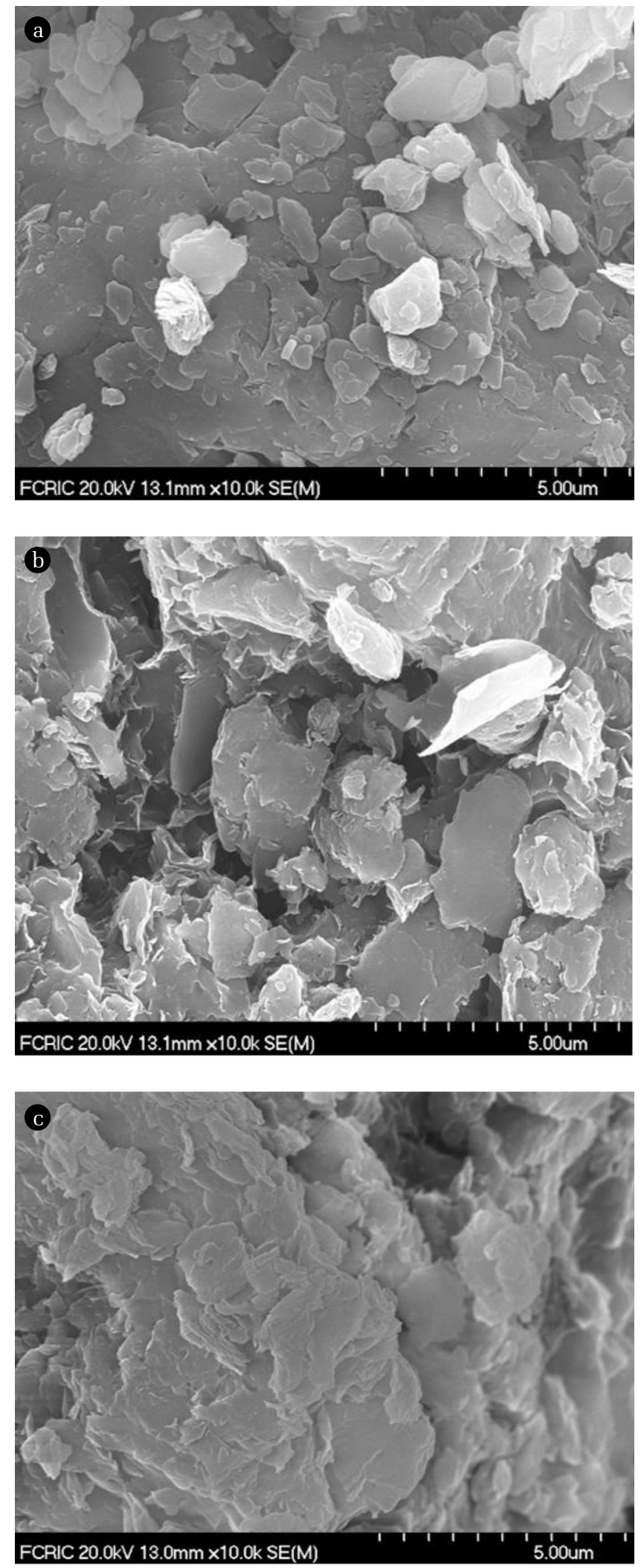

Fig. 1. SEM images of (a) pristine bentonite (Bn) (b) $\mathrm{BnH}$ (c) $\mathrm{BnAH}$ solids. 
due to the high content of illite, smectite and kaolinite compared to the silica content. The modified materials caused an increase in the pore size and pore volume of materials whereas the BET specific surface area was decreased significantly. These results further showed that the interspace of bentonite is occupied by HDTMA or aluminium leading to decrease in specific surface area while the pore volume and pores sized is enhanced due to propping up of the interlayer.

The surface morphology of pristine clay and modified clay solids were studied by the FE-SEM imaging and presented in Fig. 1. It is evident from the figure that the surface of pristine bentonite is ordered and possesses a compact structure. However, the hybrid materials $(\mathrm{BnH})$ surface showed disordered and heterogeneous structure with enhanced porosity. It is assumed that the interspace of bentonite was occupied by the HDTMA molecule by exchanging or replacing the cations and water molecules. Similarly, the hybrid material $(\mathrm{BnAH})$ showed similar heterogeneous structure and the surface contained with dispersed fine particles, possibly due to the aggregation of aluminium or the structure of clay sheet is pillared with aluminium as soon as it entered within the interspace of clay.

\subsection{Batch Reactor Operations}

\subsubsection{Effect of $\mathrm{pH}$ on the removal of $A Y$}

Alizarin yellow is a class of azo dye group and exceedingly rich with organic contents along with associated toxicity. The complex structure of alizarin yellow having with aromatic rings makes the compound persistent in nature hence, found difficult in biodegradation. Therefore, it received greater attention for its complete elimination/or degradation from wastewater treatment plants $[6,10]$. The $\mathrm{pH}$ dependent removal of AY by both the pristine bentonite $(\mathrm{Bn})$ and hybrid materials $(\mathrm{BnH}$ and $\mathrm{BnAH})$ is conducted within the $\mathrm{pH} 4.0-10.0$ and the results are plotted as percent removal of AY against the final $\mathrm{pH}$ (Fig. 2). The $\mathrm{pH}_{\mathrm{pzc}}$ of these materials are 10.1, 8.4, 6.3 for $\mathrm{Bn}, \mathrm{BnH}$ and $\mathrm{BnAH}$, respectively. It is evident ite clay $(\mathrm{Bn})$ is insignificant while a very high uptake of AY is

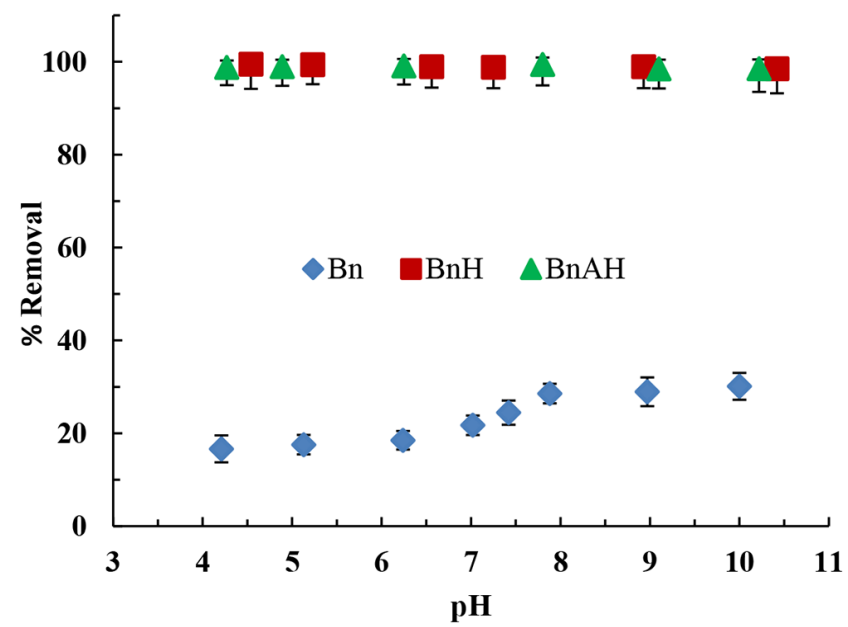

Fig. 2. $\mathrm{pH}$ dependence removal of Alizarin Yellow using pristine bentonite and hybrid materials [Concentration of AY: $10.0 \mathrm{mgL}^{-1}$; Temperature: $25^{\circ} \mathrm{C}$. from the figure that the percentage removal of AY by pristine bentonachieved by these hybrid materials. Almost $100 \%$ of AY is removed in all the studied $\mathrm{pH}$ range which is independent of the change in $\mathrm{pH}$ and the charge possessed by these hybrid materials, even though the $\mathrm{pH}_{\mathrm{pzc}}$ of $\mathrm{BnH}$ and $\mathrm{BnAH}$ is 8.4 and 6.3, respectively. A very high uptake of AY by these materials is due to the intercalation of HDTMA within the clay network which enhanced the hydrophobicity and organophilicity of the clay surface and enabled the removal of AY [30-33]. Moreover, very high uptake of AY by these hybrid materials showed the high affinity of hybrid materials towards the AY. The enhanced hydrophobic nature of the hybrid materials is useful in the remediation of aqueous solutions contaminated with variety of micro-pollutants or even variety of dye compounds.

\subsubsection{Time dependence removal}

The time dependent removal of AY by these hybrid materials is conducted at different intervals of time and results are shown in Fig. 3. The uptake of AY by these materials is very rapid which is primarily due to the availability of active sites on the hybrid materials. It is noted that within 5 to $10 \mathrm{~min}$ of contact an apparent equilibrium was reached as 98 and $97 \%$ of AY was removed by the $\mathrm{BnH}$ and $\mathrm{BnAH}$ solids, respectively. The result showed that a strong affinity of these hybrid materials is possessed at least towards the AY molecules.

Further, the non-linear kinetic models i.e., the pseudo-first order (PFO), pseudo-second order (PSO) and fractal like pseudo-second order (FLPSO) were utilized to fit the time dependence removal data [35]. The least square sum and assessed values of the unknown parameters are obtained by using the 'solver' from Microsoft Excel software adds-in and results are returned in Table S1. It is evident from the kinetic fitting that the kinetic data is fitted well to the PSO and FL-PSO model compared to the PFO model since relatively low least square sum is obtained for these two kinetic models. The results further pointed out that AY are bound to the surface of hybrid materials with relatively strong forces and the mechanisms involved is expected to be 'chemisorption'. The sorption of Alizarin

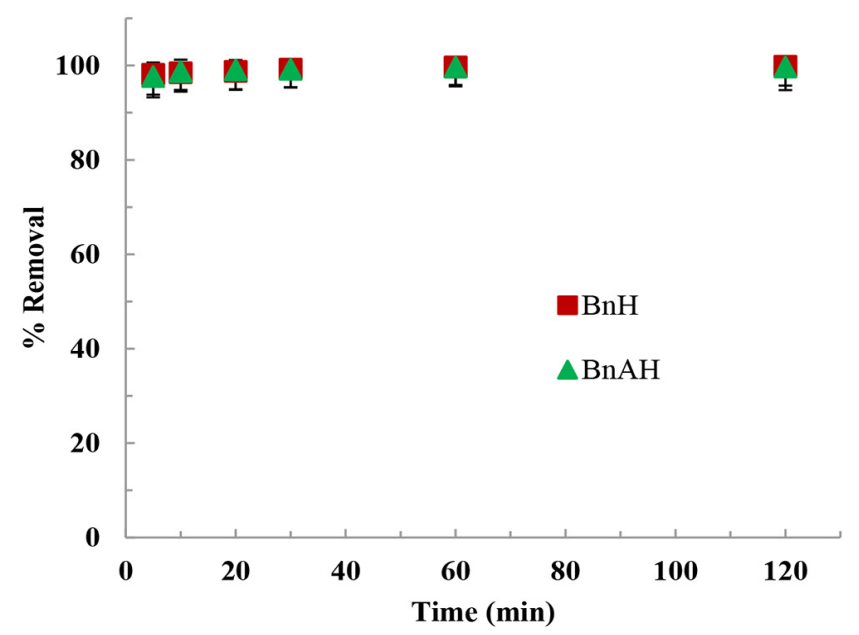

Fig. 3. Removal of Alizarin Yellow by hybrid materials as a function of time [Concentration of AY: $10.0 \mathrm{mgL}^{-1} ; \mathrm{pH}$ : 7.0; Temperature: $25^{\circ} \mathrm{C}$. 
Yellow and Alizarin Red by polypyrrole-coated magnetic nanoparticles also followed pseudo-second order kinetics [36]. Similar results were reported previously on modified nanoalumina as sorbent for the removal of Alizarin Yellow R and Methylene Blue Dyes [37].

\subsubsection{Concentration dependence studies}

The sorptive concentration dependence study for AY was conducted to estimate the removal efficiency of the modified material for Alizarin Yellow with the varied initial AY concentrations from 100.0 to $500.0 \mathrm{mgL}^{-1}$ at constant $\mathrm{pH}$ 7.0. The results are presented in Fig. 4. It is observed that on increasing the concentration of AY from 100.0 to $500.0 \mathrm{mgL}^{-1}$ the percentage removal of AY by $\mathrm{BnH}$ and $\mathrm{BnAH}$ decreased from 86.7 to $36.7 \%$ and 99.4 to $62.5 \%$, respectively. These results further suggested that the hybrid materials are having strong affinity towards AY.

Further, the concentration dependent data are utilized to conduct the isotherm modelling, i.e., Langmuir and Freundlich adsorption isotherm [38]. The isotherm constants i.e., Langmuir monolayer sorption capacity $\left(q_{o}\right)$, Langmuir constant $(b)$ and Freundlich constants $\left(K_{f}\right.$ and $\left.1 / n\right)$ are evaluated and given in Table 1 . Higher value of $R^{2}$ is obtained for Langmuir adsorption isotherm for AY, which inferred the applicability of Langmuir adsorption isotherm. The Langmuir monolayer capacity is found to be 106.9 and 166.67 $\mathrm{mgg}^{-1}$ for $\mathrm{BnH}$ and $\mathrm{BnAH}$ solids, respectively. Previous study reported that the removal of alizarin yellow and phenol red using amine rich functionalized mesoporous silica (Ar@MCM) was found to follow Langmuir adsorption isotherm [39]. It was also reported that the adsorption of AY using pine cone char, walnut shell char,

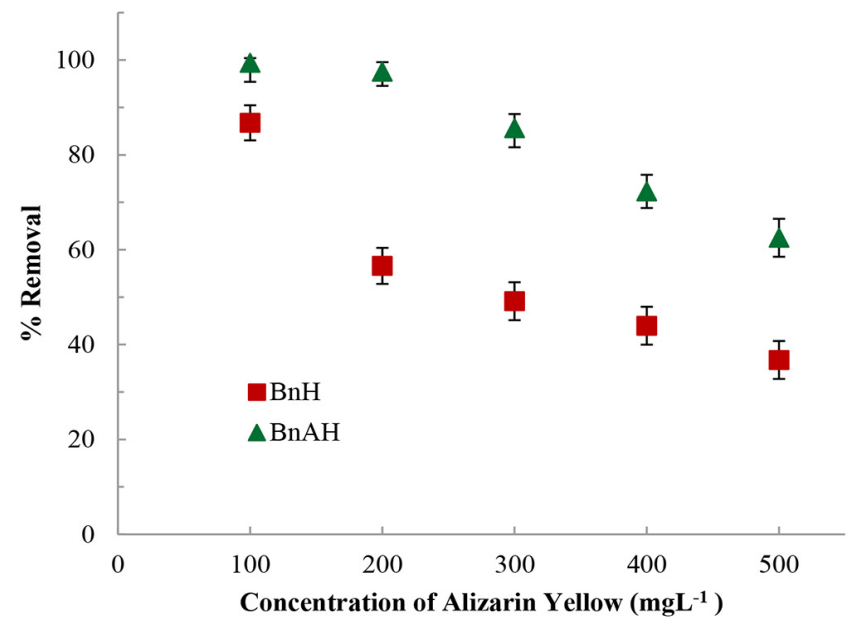

Fig. 4. Removal of AY by hybrid materials as a function of $\mathrm{AY}$ concentration [pH: 7.0; Temperature: $25^{\circ} \mathrm{C}$.

and hazelnut shell char follows Langmuir adsorption isotherm better than Freundlich adsorption isotherm [40]. Furthermore, comparison table for the maximum adsorption capacity of alizarin yellow using various adsorbents along with $\mathrm{BnH}$ and $\mathrm{BnAH}$ are given in Table 2. It is observed that the maximum adsorption capacity of $\mathrm{BnH}$ is comparable or higher than other adsorbents presented in this table. Furthermore, it is interesting to observe that the $\mathrm{BnAH}$ solids possessed relatively high adsorption capacity for AY.

\subsubsection{Effect of co-existing ions}

The removal of Alizarin Yellow by these hybrid materials were

Table 1. Langmuir and Freundlich Constants Estimated for the Adsorption of AY Using BnH and BnAH

\begin{tabular}{lcccccc}
\hline \multirow{2}{*}{ Material } & \multicolumn{3}{c}{ Langmuir } & \multicolumn{3}{c}{ Freundlich } \\
\cline { 2 - 7 } & $\boldsymbol{q}_{\boldsymbol{o}}(\mathbf{m g} / \mathbf{g})$ & $\boldsymbol{b}(\mathbf{L} / \mathbf{g})$ & $\boldsymbol{R}^{2}$ & $\mathbf{1} / \mathbf{n}$ & $\boldsymbol{K}_{\boldsymbol{f}}(\mathbf{m g} / \mathbf{g})$ & $\boldsymbol{R}^{\mathbf{2}}$ \\
\hline $\mathrm{BnH}$ & 108.69 & 0.019 & 0.963 & 0.256 & 20.994 & 0.914 \\
\hline $\mathrm{BnAH}$ & 166.66 & 0.158 & 0.994 & 0.197 & 60.687 & 0.964 \\
\hline
\end{tabular}

Table 2. Maximum Adsorption Capacity of Alizarin Yellow Using Different Adsorbents

\begin{tabular}{|c|c|c|c|}
\hline Sl. No & Adsorbents & Maximum adsorption capacity $\left(\mathrm{mg} \mathrm{g}^{-1}\right)$ & Reference \\
\hline 1 & Saccharum spontaneum & 3.42 & [41] \\
\hline 2 & Polypyrrole-coated $\mathrm{Fe}_{3} \mathrm{O}_{4} \mathrm{NPs}$ & 113.6 & [36] \\
\hline 3 & Acid treated corn stalk & 4.01 & {$[42]$} \\
\hline 4 & Biosorbent casuarina equisetifolla & 13.51 & [43] \\
\hline 5 & Pisum sativum peels & 2.47 & {$[44]$} \\
\hline 6 & $\gamma$-Alumina & 37.7 & {$[37]$} \\
\hline 7 & DNPH- $\gamma$-alumina & 47.8 & [37] \\
\hline 8 & Maghemite iron oxide $\left(\gamma-\mathrm{Fe}_{2} \mathrm{O}_{3}\right)$ NPs & 23.2 & [45] \\
\hline 9 & MCM41@Cu-Fe-LDH & 121 & {$[46]$} \\
\hline 10 & Layered double hydroxide (LDH) & 4.68 & {$[47]$} \\
\hline 11 & $\mathrm{BnH}$ & 108.7 & Present study \\
\hline 12 & $\mathrm{BnAH}$ & 166.7 & Present study \\
\hline
\end{tabular}



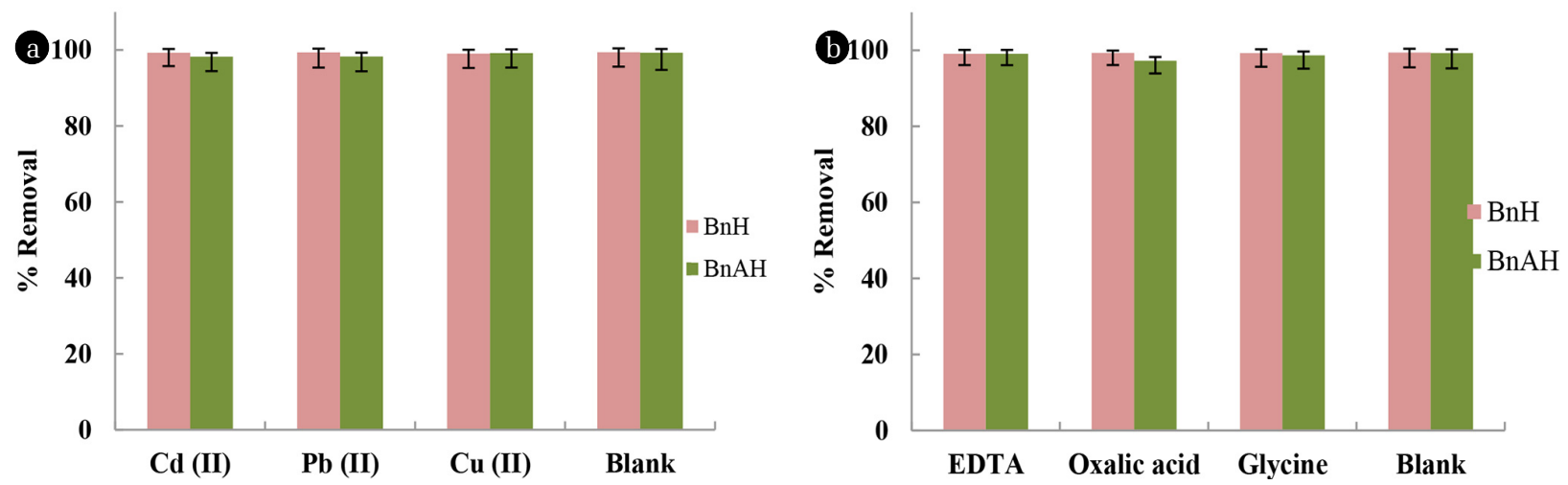

Fig. 5. Removal of Alizarin Yellow by hybrid materials in presence of several co-existing ions [Concentration of $\mathrm{AY}^{\mathrm{C}} 10.0 \mathrm{mgL}^{-1}$; $\mathrm{concentration}^{-}$ of co-existing ions: $50.0 \mathrm{mgL}^{-1}$; $\mathrm{pH}$ : 7.0 ; Temperature: $25^{\circ} \mathrm{C}$.

also conducted in the presence of other co-existing ions. The presence of co-existing ions perhaps inhibited the uptake of water contaminants by the adsorbents; therefore, the heavy metals ions (Cd(II), $\mathrm{Pb}$ (II) and $\mathrm{Cu}(\mathrm{II})$ ) which are commonly found in wastewater along with other anions were taken as co-existing ions. Fig. 5 indicated that the presence of other cations viz., $\mathrm{Cd}(\mathrm{II}), \mathrm{Pb}(\mathrm{II})$ and $\mathrm{Cu}(\mathrm{II})$ or anions viz., EDTA, oxalic acid, and glycine in aqueous solution did not affect the removal of AY by these hybrid materials. This again reveals that these hybrid materials show selectivity and greater applicability towards the removal of AY. The materials have shown applicability even in the real matrix and complex matrix for remediation of aqueous solutions contaminated with AY.

\subsubsection{Effect of background electrolyte concentrations}

The sorption of AY in presence of background electrolyte $(\mathrm{NaCl})$ concentrations is studied using these hybrid materials. The background electrolyte concentration is eventually demonstrating the phenomenon occurred at the solid/solution boundary [48, 49]. The change in background electrolyte concentrations is not generally influenced by specific sorption, but the change in background electrolyte concentration has a great impact on non-specific sorption [34].

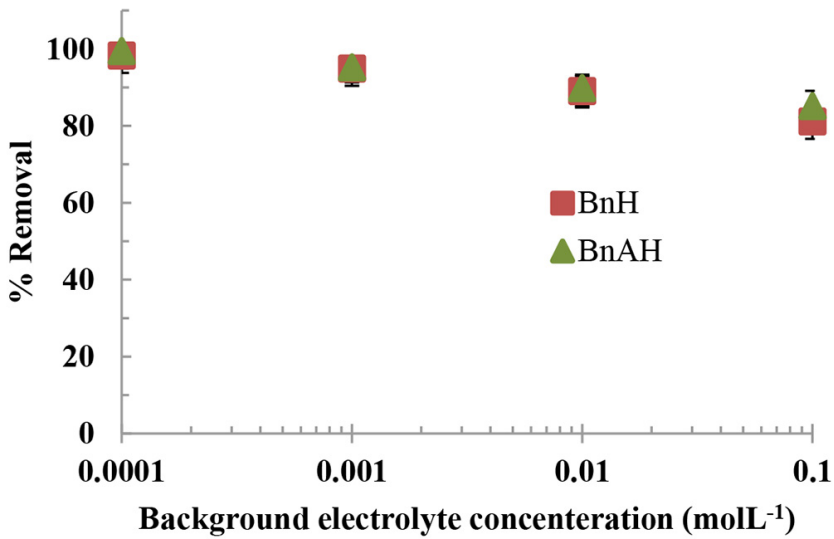

Fig. 6. The effect of background electrolyte concentration $(\mathrm{NaCl})$ on the removal of $\mathrm{AY}$ by $\mathrm{BnH}$ and $\mathrm{BnAH}$ [Concentration of $\mathrm{AY}$ : $100.0 \mathrm{mgL}^{-1} ; \mathrm{pH}$ : 7.0; Temperature: $\left.25^{\circ} \mathrm{C}\right]$.
Therefore, the sorption of AY is performed by varying the concentrations of background electrolyte from 0.0001 to $0.1 \mathrm{molL}^{-1}$ at a constant $\mathrm{pH}$ of 7.0 and at initial AY concentration of $100 \mathrm{mgL}^{-1}$. The results are shown in Fig. 6 which implies that the increase in background electrolyte concentrations from 0.0001 to $0.1 \mathrm{molL}^{-1}$ the percent uptake of $\mathrm{AY}$ by $\mathrm{BnH}$ and $\mathrm{BnAH}$ decreased from 98.2 to $81.2 \%$ and 99.4 to $85.1 \%$, respectively. Therefore, the 1,000 times increase in background electrolyte concentrations did not considerably affect the removal of $\mathrm{AY}$ by $\mathrm{BnH}$ and $\mathrm{BnAH}$ which shows a strong affinity of these hybrid materials towards AY.

\subsubsection{Application to real wastewater sample}

The applicability of $\mathrm{BnH}$ and $\mathrm{BnAH}$ were assessed for the removal of AY from real wastewater samples collected from municipal wastewater treatment plant, Chite, Aizawl Mizoram, India. The $\mathrm{pH}$ of wastewater was found to be 6.89. The analysis results showed that the real water sample contained 0.23 and $0.10 \mathrm{mgL}^{-1}$ of $\mathrm{Ca}$ and Ni, respectively (Table S2). Additionally, the water is contained with high content of inorganic and organic carbon. The sulfate and nitrate are having high value. Further, the real water sample was spiked with AY by maintaining its concentrations at 100.0 $\mathrm{mgL}^{-1}$. The percent removal of AY from real water sample using $\mathrm{BnH}$ and $\mathrm{BnAH}$ were found to be 96.25 and $98.85 \%$, respectively. This study showed that the removal efficiency of AY using these hybrid materials in real wastewater sample is similar to the results observed in purified water. Therefore, it can be concluded that the hybrid materials ( $\mathrm{BnH}$ and $\mathrm{BnAH}$ ) possessed high selectivity and applicability for removal of AY in real water matrix.

\section{Conclusions}

The HDTMA modified bentonite $(\mathrm{BnH})$, and pillared bentonite with $\mathrm{Al}$ and modified with HDTMA (BnAH) are employed for the removal of Alizarin yellow from aqueous solutions. The SEM images of solids showed the heterogeneous surface structure of $\mathrm{BnH}$ material whereas fine particles of aluminium hydroxides are observed onto the BnAH solid. Batch reactor studies indicated that the hybrid materials showed strong affinity towards the Alizarin Yellow and the change in $\mathrm{pH}(4.0-10.0)$ and concentration of AY (1.0-25.0 $\mathrm{mgL}^{-1}$ ) could not affect the removal of AY using these solids. A 
rapid uptake of AY achieved an apparent equilibrium within 5-10 min of contact and followed pseudo-second order kinetics using these hybrid materials. Moreover, increased background electrolyte (NaCl) concentrations (0.0001-0.1 molL ${ }^{-1}$ ) and the presence of co-existing ions have not affected very high percent removal of AY by these hybrid materials. The hybrid materials are increasingly organophilic in nature and the AY molecule was attached with strong chemical forces on the surface of hybrid materials. The hybrid materials hence, showed greater applicability in the remediation of aquatic environments contaminated with Alizarin Yellow dye.

\section{Acknowledgments}

This article was presented at 2nd Annual Convention of North East (India) Academy of Science \& Technology (NEAST) held on 16-18 November 2020 in Mizoram, India.

\section{Author Contributions}

R.M. (Ph.D. Student) conducted the sorption experiments. S. (Ph.D. Student) helped in the experiments and compiling the data. T. (Associate Professor) has prepared the hybrid materials and helped in characterization of solids. D.T. (Professor) formulated the problem and wrote the manuscript. S.M.L. (Professor) has gone through the manuscript and made necessary corrections in the manuscript.

\section{References}

1. Fu F, Gao Z, Gao L, Li D. Effective adsorption of anionic dye, Alizarin Red S, from aqueous solutions on activated clay modified by iron oxide. Ind. Eng. Chem. Res. 2011;50(16):9712-9717.

2. Fewson CA, Biodegradation of xenobiotic and other persistent compounds: the causes of recalcitrance. Trends Biotechnol. 1988;6(7):148-153.

3. Dos Santos AB, Cervantes FJ, Yaya-Beas RE, Van Lier JB. Effect of redox mediator, AQDS, on the decolourisation of a reactive azo dye containing tri489 azine group in a thermophilic anaerobic EGSB reactor. Enzyme Microb. Technol. 2003;33(7):942-951.

4. Brown D. Effects of colorants in the aquatic environment. Ecotoxicol. Environ. Saf. 1987;13(2):139-147.

5. Shawabkeh RA, Tutunji MF. Experimental study and modeling of basic dye sorption by diatomaceous clay. Appl. Clay Sci. 2003;24(1-2):111-112.

6. Lalliansanga, Tiwari D, Tiwari A, et al. Facile synthesis and characterization of nanocomposite $\mathrm{Au}^{0}(\mathrm{NPs}) /$ titanium dioxide: Photocatalytic degradation of Alizarin Yellow. J. Ind. Eng Chem. 2020;82:153-163.

7. Fu Y, Viraraghavan T. Fungal decolorization of dye wastewater. Bioresour. Technol. 2001;79:251-262.

8. Zhou Y, Lu J, Zhou Y, Liu Y. Recent advances for dyes removal using novel adsorbents: A review. Enviro. Pollut. 2019;252:352-365.

9. Pandey S, Ramontja J. Natural Bentonite Clay and Its Composites for Dye Removal: Current State and Future Potential. Am. J. Chem. Appl. 2016;3(2):8-19.

10. Tiwari D, Lalhriatpuia C, Lalhmunsiama, Lee SM, Kong SH. Efficient application of nano-TiO2 thin films in the photocatalytic removal of Alizarin Yellow from aqueous solutions. Appl. Surf. Sci. 2015;353:275-283.

11. Lalliansanga, Tiwari D, Tiwari A, et al. Facile synthesis and characterization of $\mathrm{Ag}(\mathrm{NP}) / \mathrm{TiO} 2$ nanocomposite: Photocatalytic efficiency of catalyst for oxidative removal of Alizarin Yellow. J. Ind. Eng. Chem. 2020;82:153-163.

12. Wang H, Yuan X, Zeng G, et al. Removal of malachite green dye from wastewater by different organic acid-modified natural adsorbent: kinetics, equilibriums, mechanisms, practical application, and disposal of dye-loaded adsorbent. Environ. Sci. Pollut. Res. Int. 2014;21:11552-11564.

13. Araujo CK, Oliveira GR, Fernandes NS, et al. Electrochemical removal of synthetic textile dyes from 500 aqueous solutions using Ti/Pt anode: role of dye structure. Environ. Sci. Pollut. Res. Int. 2014;21:9777-9784.

14. Abbasi M. Synthesis and characterization of magnetic nanocomposite of chitosan/ $\mathrm{SiO}_{2} /$ carbon nanotubes and its application for dyes removal. J. Clean. Prod. 2017;145:105-113.

15. Zhu Y, Kolar P. Adsorptive removal of p-cresol using coconut shell-activated char. J. Environ. Chem. Eng. 2014;2:2050-2058.

16. Wang S, Wu H. Environmental-benign utilization of fly ash as low-cost adsorbents. J. Hazard. Mater. 2006;136:482-501.

17. Yang YX, Ma J, Qin QD, Zhai XD. Degradation of nitrobenzene by nano- $\mathrm{TiO}_{2}$ catalyzed ozonation. J. Mol. Catal. A Chem. 2007;267:41-48.

18. Huang Y, Li J, Chen X, Wang X. Applications of conjugated polymer based composites in wastewater purification. Rsc Adv. 2014;4:62160-62178.

19. Zhang S, Zeng M, Xu W, et al. Polyaniline nanorods dotted on graphene oxide nanosheets as a novel super adsorbent for Cr (VI). Dalton Trans. 2013;42:7854-7858.

20. Shao D, Hou G, Li J, Wen T, Ren X, Wang X. PANI/GO as a super adsorbent for the selective adsorption of uranium. Chem. Eng. J. 2014;255:604-612.

21. Lee SM, Tiwari D. Organo and inorgano-organo-modified clays in the remediation of aqueous solutions: An overview. Appl. Clay Sci. 2012;59-60:84-102.

22. Ngulube T, Gumbo JR, Masindi V, Maity A. An update on synthetic dyes adsorption onto clay based minerals: a state-of-art review. J. Environ. Manag. 2017;191:35-57.

23. Şahan T, Erol F, Yılmaz S. Mercury(II) adsorption by a novel adsorbent mercapto-modified bentonite using ICP-OES and use of response surface methodology for optimization. Microchem. J. 2018;138:360-368.

24. Prabhu PP, Prabhu B. A review on removal of heavy metal ions from waste water using natural/ modified bentonite. MATEC Web Conf. 2018;144:02021.

25. Bergaya F, Lagaly G. General introduction: clays, clay minerals, and clay science. Dev. Clay Sci. 2006;1:1-18.

26. Murray HH. Traditional and new applications for kaolin, smectite, and palygorskite: A general overview. J. Colloid. Interface. Sci. 2007;315:191-199.

27. Harvey CC, Murray HH. Industrial clays in the 21st century: 
A perspective of exploration, technology and utilization. Appl. Clay Sci. 1997;11:285-310.

28. Konta J. Clay and man: clay raw materials in the service of man. Appl. Clay Sci. 1995;10:275-335.

29. Andrunik M, Bajda T. Modification of bentonite with cationic and nonionic surfactants: Structural and textural features. Materials 2019;12:3772.

30. Thanhmingliana, Tiwari D. Efficient use of hybrid materials in the remediation of aquatic environment contaminated with micro-pollutant diclofenac sodium. Chem. Eng. J. 2015;263: 364-373.

31. Tiwari D, Lee SM. Novel hybrid materials in the remediation of ground waters contaminated with $\mathrm{As}(\mathrm{III})$ and $\mathrm{As}(\mathrm{V})$. Chem. Eng. J. 2012;204-206:23-31.

32. Lalhmunsiama, Lee SM, Tiwari D. Manganese oxide immobilized activated carbons in the remediation of aqueous wastes contaminated with copper(II) and lead(II). Chem. Eng. J. 2013;225:128-137.

33. Rivera-Utrilla J, Bautista-Toledo I, Ferro-García MA, Moreno-Castilla C. Activated carbon surface modifications by adsorption of bacteria and their effect on aqueous lead adsorption. J. Chem. Technol. Biotechnol. 2001;76:1209-1215

34. Thanhmingliana, Lee SM, Tiwari D, Prasad SK. Efficient attenuation of 17a-ethynylestradiol (EE2) and tetracycline using novel hybrid materials: batch and column reactor studies. RSC Adv. 2015;5:46834-46842.

35. Lalchhingpuii, Lee SM, Tiwari D. Synthesis and Characterization of Chitosan templated Mesoporous Silica: Efficient use of Mesoporous Silica in the removal of $\mathrm{Cu}(\mathrm{II})$ from Aqueous Solutions. Sci. Technol. J. 2016;4:105-112.

36. Gholivand MB, Yamini Y, Dayeni M, Seidi S, Tahmasebi E. Adsorptive removal of alizarin red-S and alizarin yellow GG from aqueous solutions using polypyrrole-coated magnetic nanoparticles. J. Environ. Chem. Eng. 2015;3:529-540.

37. Al-Rubayee WT, Abdul-Rasheed OF, Ali NM. Preparation of a Modified Nanoalumina Sorbent for the Removal of Alizarin Yellow R and Methylene Blue Dyes from Aqueous Solutions. J. Chem. 2016;2016:4683859.

38. Balarak D, Mahdavi Y, Mostafapour F. Application of Alumina-coated Carbon Nanotubes in Removal of Tetracycline from Aqueous Solution. Br. J. Pharm. Res. 2016;12:1-11.
39. Adlnasab L, Shabanian M, Ezoddin M, Maghsodi A. Amine rich functionalized mesoporous silica for the effective removal of alizarin yellow and phenol red dyes from waste waters based on response surface methodology. Mater. Sci. Eng. B. 2017;226:188-198.

40. Kaya N, Yildiz Uzun Z. Investigation of effectiveness of pyrolysis products on removal of alizarin yellow GG from aqueous solution: a comparative study with commercial activated carbon. Water. Sci. Technol. 2020;81:1191-1208.

41. Narayanan AL, Dhamodaran M, Solomon JS. Thermodynamics and kinetics of adsorption of Alizarin yellow from aqueous solutions on Saccharum spontaneum. Int. J. Eng. Appl. Sci. 2015;2:63-69.

42. Ismail MI, Fadzil MSM, Rosmadi NNF, et al. Acid treated corn stalk adsorbent for removal of alizarin yellow dye in wastewater. J. Phys. Conf. Ser. 2019;1349:012105.

43. Martin DP, Samu SJ. Adsorption modeling of alizarin yellow on biosorbent Casuarina equisetifolla. Int. J. Res. Chem. Environ. 2011;1:201-212.

44. Rehman R, Mahmud T, Arshad A. Removal of Alizarin Yellow and Murexide Dyes from Water Using Formalin Treated Pisum sativum Peels. Asian. J. Chem. 2015;27:1593.

45. Badran I, Khalaf R. Adsorptive removal of alizarin dye from wastewater using maghemite nanoadsorbents. Sep. Sci. Technol. 2020;55:2433-2448

46. Adlnasab L, Ezoddin M, Karimi MA, Hatamikia N. MCM-41@ $\mathrm{Cu}-\mathrm{Fe}-\mathrm{LDH}$ magnetic nanoparticles modified with cationic surfactant for removal of Alizarin Yellow from water samples and its determination with HPLC. Res. Chem. Intermed. 2018;44 3249-3265.

47. Al-Salihi KJ, Alfatlawi WR. Synthesis and characterization of low-cost adsorbent and used for Alizarin yellow GG and alizarin Red S dyes removal from aqueous solutions. IOP Conf. Ser. Mater. Sci. Eng. 2021;1094:012175.

48. Hayes KF, Papelis C, Leckie JO. Modeling ionic strength effects on anion adsorption at hydrous oxide/solution interfaces. $J$. Colloid. Interface. Sci. 1988;125:717-726.

49. Lee SM, Tiwari D. Sericite in the remediation of Cd (II)-and Mn (II)-contaminated waters: batch and column studies. Environ. Sci. Pollut. Res. 2014;21:3686-3696. 